\title{
Innovation in Healthcare Delivery Systems: An Analysis on Burden of Diseases
}

\begin{abstract}
Keywords
Health; Healthcare services; Diseases

Abstract

Health care delivery systems will have to gear up to take up necessary preventive, curative, primitive and rehabilita tive healthca re for the population. The challenge of building rural health services, state's responsibility in providing these and training paramedical personnel to camy out limited curative and preventive responsibilities were part of any country's development thinking before and after independence. The rising expectations of healthcare users mean that the way the services are organized and delivered will become significant. It is, therefore, essential to understand how best to organize and deliver healthcare services. The adoption of ICT in the healthcare sector has brought about several benefits namely, greater productivity, profitability, efficiency, faster service, customer satisfaction, customer convenience, operational flexibility, $24 \times 7$ operations, space and cost savings. Many innovative applications of ICT in the healthcare sector have bridged the communic ation gap between the patients, doctors and various stakeholders.
\end{abstract}

\section{Introduction}

The set of arrangements for the provision of healthcare in a country is usually referred to as its "Healthcare system". Systems vary considerably from one nation to the other, both in the extent of responsibility assumed by the government for the provision of healthcare and in the managerial control of administrations. At one extreme, it is a totally free enterprise system, in which all administrations are purchased and paid for by the consumer in an open market basis, as per his apparent needs and his capacity to pay. While on the other extreme, it is a completely socialized system in which the government assumes full responsibility for the healthcare of all its citizens. In few nations, the system is centrally controlled, that is, all administrations are regulated by one central agency; in other, a multiplicity of agencies provides services. Between the extremes are a wide variety of systems.

Challenges faced by the health sector need a review and issues, such as health sector governance and organization, burden of disease, occurrence of natural disasters, condition of women and children; as well as anticipation of issues in the future.

The range of services covered by the government-sponsored program varies from one province to the other. All provincial plans must provide basic hospital and medical care services. Some include extra advantages, for example pharmaceutical administrations, foot care administrations, and eye care administrations. Various numbers of individuals supplement the government program with private

\section{Journal of \\ Clinical Trials \& Patenting}

\author{
Mohammad Chand Jamali* \\ Department of Health \& Medical Sciences, Khawarizmi International \\ College, United Arab Emirates \\ *Address for Correspondence: \\ Mohammad Chand Jamali, Department of Health \& Medical Sciences, \\ Khawarizmi International College, 25669, Abu Dhabi, United Arab \\ Emirates, E-mail: mjamali68@gmail.com \\ Submission: 07 February, 2017 \\ Accepted: 27 April, 2017 \\ Published: 03 May, 2017 \\ Copyright: ๑ 2017 Jamali MC. This is an open access article distributed \\ under the Creative Commons Attribution License, which permits \\ unrestricted use, distribution, and reproduction in any medium, provided \\ the original work is properly cited.
}

insurance plans to cover extra cost they may cause, for example, the expense for private or semiprivate accommodations in a clinic, or else to give salary security in case of illness. In addition, industrial and commercial firms frequently offer supplementary advantages, such as dental protection, to their workers on a business representative costshared basis. As in the United States, industrial firms additionally partake in the financing of health clinics and hospitals in some instances.

India is a Democratic Republic comprising of 28 States and 7 Union Territories (straightforwardly administered by the Central Government). As indicated by the Constitution of India, state governments have jurisdiction over public health, sanitation and doctor's facilities while the Central Government is responsible for medical education. State and Central Governments have concurrent jurisdiction over food and drug administration, and family welfare. Despite the fact that health is the responsibility of the states, under the Constitution, the Central Government has been financing the national aliment control, family welfare and regenerative and further more the programs that are related to child health. Each state, accordingly, has built its own particular arrangement of Health care delivery, free of the Central Government.

In India, public spending on healthcare is low compared to the developed countries, having declined from 1.3\% of GDP in 1990 to $0.9 \%$ of GDP in 1999 . The Government, in its National Health Policy, 2002 (NHP 2002), is targeting an increase of healthcare expenditure to $6 \%$ of GDP by 2010 , with $2 \%$ of GDP being funded by public health investment. Today's public spending on health is a negligible $1 \%$ of GDP ascertained in India Budget 2011-2012. Public spending on health care according to the World Health Organization suggests ought to be no less than $5 \%$. The government administration throughout the most recent six years has not possessed the capacity to move towards its own objective of $3 \%$ of GDP for health. The share of the Central government in public spending for health is an insignificant $0.25 \%$ of GDP when according to the UPA target it should be $40 \%$ of $3 \%$ of GDP that is $1.2 \%$ of GDP or Rs. 86,400 crores at today's prices. 
The official representing assemblages of the health system at the national level comprise of

(a) The Ministry of Health and Family Welfare

(b) The Directorate General of Health Services and

(c) The Central Council of Health and Family Welfare.

At the state level the healthcare administration comprises

(a) State Ministry of Health

(b) State Health Directorate and District Medical and Health Officer (DMHO) at the district level

The Central responsibility comprises mainly of policy making, planning, directing, helping, evaluating and planning the work of the State Health Ministers, which the goal that health administration cover all aspects of the country and know state lags behind for need of these services.

Historically, the first turning point in State Health Administration was the year 1919, when the states acquired autonomy, under the Montague-Chelmsford changes from the Central government in matters of public health. The Government of India act 1935 gave facilitates autonomy to the states. The position has to a great extent continued as before even after the new Constitution of India came into force in 1950. The state is the ultimate authority responsible for all the health administration working within its jurisdiction.

\section{Review of Literature}

The domain of the term "Health" is as large and complex as the entire scope of human activities [1]. Professional, technical, and supportive health workers may view healthcare as the provision of a range of healthcare services with in-patient, out-patient and home health facilities. The development of healthcare facilities is influenced not only by the opening of hospitals or healthcare centers, but also by their proper administration and management.

The WHO as "A programs that should make available to the individual and thereby to the community, all facilities and allied sciences necessary to promote and maintain the health of mind and body has defined health care [2]. Health care remains one of the most important human endeavors to improve the quality of life. The main objective of any healthcare system is to facilitate the achievement of optimal level of health to the community through the delivery of services of appropriate quality and quantity. Increasing the availability, accessibility and awareness about the services and technological advances for the management of health problems, raising expectations of the people, and the ever-escalating cost of healthcare are some of the challenges that the healthcare systems have to cope up with.

The concept of health centre was first brought by Lord Dawson in England during 1920. As early as 1928, Govt. of Mysore established the first health unit in the country at Mandya (in Karnataka). Establishment of health centers at Nazafgarh, Singur, Poonamallie, Trivandrum, and Lucknow and at other places in collaboration with Rockefeller Foundation and Govt. of India between 1931 and 1939 was an important landmark in the history of health care delivery system [3].
Community-based primary health care is the mainstay of health care delivery to persons in developing countries. In these countries, primary care must be accessible to the vast majority of the population as poor access to primary health care is associated with adverse pregnancy outcomes, infant mortality and decreased vaccination coverage [4-8]. In accessibility of health care facilities may also affect adherence to treatment regime. Access to health services in the developing world is poor, but it gets significantly worse in the rural areas.

World Health Organization (2009) in its study on increasing access to health workers in remote and rural health areas found that there are many problems of geographical mal distribution rather than a lack of physicians [9]. The movements of health workers in general, such as turnover rates, absenteeism, unemployment or dual employment have a correlation between the factors influencing the choices and decisions of health workers to practice in remote and rural areas and the categories of interventions that could respond to those factors. The deepest concerns of health workers when it comes to practicing in remote and rural areas are those related to the socioeconomic environment, such as working and living conditions, access to education for children, availability of employment for spouses, insecurity and work overload.

Lewando Hundt et al. found in their study that there are issues of accessibility in terms of distance, and of acceptability in relation to the lack of local and female staff, lack of cultural competencies and poor communication [10]. Also, they found that these providers of health care have a developing partnership that could potentially address the challenge of provision to this rural area.

Frank Tanser found out in their study that the population level increase in accessibility achieved by the construction of the test clinic (location optimized by PHIT methodology) would be 3.6 times [11]. The increase in accessibility was achieved by the construction of the newest clinic. The corresponding ratio for increasing clinic coverage (\% of population within 60 minutes of care) would be 4.7 and also develop a model through Person Hours of Travel Time (PHIT) methodology for health planners to identify potential localities for establishing new health care facilities by using GIS technology to efficiently to site new facilities to achieve the maximum population level increase in accessibility to primary health care.

Ray et al. found in their study that large number of patients did not avail any services when they fall sick especially in the tribal district where distance, poor knowledge about the availability of the services and non-availability of the medicine in addition to the cost of treatment and transport [12-14]. Utilization of government health facilities was around $38 \%$ followed by unqualified practitioners and private practitioners. Referral was mostly by self or by close relatives/ families. Also attention is required with respect to the cleanliness of the premises, safe drinking water, face-lift of PHCs and SCs, clean toilet with privacy. Also, they concluded that an attempt should be made to improve utilization by cordial behavior, providing more time for patient care by the doctor, and staff, explain their prescription and report, reducing time for registration as well as waiting and finally cost of medicine they can afford [15-17].

\section{Burden of Diseases - Women and Children}

Reproductive health plays a major role and the Government strategies and programs have shifted from a target-oriented family 
planning approach to a more extensive complete strategy. Today women are more secure during their pregnancies and deliveries compared to earlier years. Despite every one of these quantities of avoidable deaths of mothers and newborns in India is still high.

The norm age of marriage has been expanding in India. However $61 \%$ of all women are married before the age of 16 . The norm age at first pregnancy is 19.2 years. Consistently in India, roughly 30 million women experience pregnancy and 27 million have live births [1]. The maternal mortality proportion, an important marker of maternal health in India, is estimated to be $301 / 100,000$ live births [2]. India has the most extreme burden of maternal mortality in the world caused due to maternal deaths in rural India and premature births.

More than $1 / 3^{\text {rd }}$ of women in India are malnourished. Among youngsters, $47 \%$ are starving and $74 \%$ are anemic and among youth $18 \%$ are malnourished. Lack of consciousness and socio-cultural taboos, just $16 \%$ of the newborns are breastfed soon after birth and $37 \%$ on the primary day just $55 \%$ of youngsters are breastfed up to 4 months [3].

Over 2.4 million youngsters' under-five yearly deaths, India represents a quarter of the global child mortality. In recent years, the eminent rate of decline of the infant mortality rate seen in the decade of the 1980s has backed off perceptibly. There are wide between and intra-state variations in infant and child mortality. A significant extent of child deaths (over $40 \%$ of under-five mortality and $64 \%$ of infant mortality) occurs in the neonatal period.

About $1 / 3^{\text {rd }}$ of the newborns have a birth-weight less than 2,500 grams (low birth-weight). A critical extent of mortality occurs in low birth-weight babies just $47.6 \%$ of children in the age group of $12-23$ months receive all the vaccinations prescribed under the Universal Immunization Program (UIP). The three major illnesses that add to mortality among children are fever (30\%), acute respiratory infection (ARI) (19\%), and diarrhea (19\%).

There are 225 million youths comprising nearly $1 / 5^{\text {th }}(22 \%)$ of any country's total population [4]. Of the total, $12 \%$ have a place with the 10-14 years age group and almost $10 \%$ are in the $15-19$ years age group. The greater part of the uneducated married females at present have been married below the legal age of marriage. Nearly $27 \%$ of the 1.5 million girls married under the age of 15 years are already mothers. More than $70 \%$ girls in the age group of $10-19$ years suffer from severe or moderate anemia [5]. Nearly $27 \%$ of married female adolescents reported unmet needs for contraception. Most sexually active adolescents are in their late adolescence. Over $35 \%$ of all reported HIV infections in India occur among young people in the age group of 15-24 years, signifying that young people are highly susceptible.

The ratio of girls to boys in the age group 0-6 years in India is becoming increasingly slanted in favor of boys. The child-sex ratio, calculated as the number of girls per 1000 boys in the $0-6$ years age group, reported by the 1991 census was 945 girls per 1000 boys. It further declined to 927 girls per 1000 boys during the 2001 census. Preference to son due to cultural, social and economic factors results in neglect of female children. Pre-natal sex determination leads to abortion of female fetuses.

\section{Burden of Diseases - Non-Communicable Diseases}

Non-communicable Diseases (NCDs), particularly Cardiovascular Diseases (CVD), diabetes mellitus, cancer, stroke and chronic lung diseases have come out as major public health issues in India, because of problems like ageing population and ecologically determined changes in behavior. Grave challenge is posed to the Indian society and its economy due to premature morbidity and mortality in the most productive phase of life. It is anticipated that in 2005 , NCDs accounted for 5,466,000 (53\%) of all deaths $(10,362,000)$ in India. The WCOICMR study on NCDs in India has estimated that the burden of diabetes mellitus, ischemic heart disease and stroke are 37.8 million, 22.4 million and 0.93 million, respectively.

One of the quick and huge growing administration parts of the world is Healthcare. Even the present health care organizations are developing by notching the hospitals with most recent service areas, and new-fangled institutes are inflowing with the stateof-art equipment, most recent technology and marketing plans. Accordingly, struggle to win in the healthcare sector is on the mount. As of not long ago, the on hand options were limited to health care consumers compared with the present ones. Above all the better earnings and consciousness levels are motivating the customers to look for quality health care. Hence, the healthcare providers need to be innovative besides offering quality services at viable prices. Hence, it does gradually more brazen out with the challenge to ensure cost effective quality care at reasonable prices. Moreover, India is also eyeing for the universal healthcare market to materialize as one of potential ends for global patients.

The execution of the hypothesis of administration quality management in the management of healthcare sector in India would go far way in developing its equipped competence ensuing in wellorganized source allotment for best advantage, least amount of depletion of the offered resource and noteworthy development in the quality delivered, ensuring a value addition to the patient. Basically, a hospital has both moral and legal responsibilities so as to meet the quality of care by protecting the interests of the patients. While this kind of concern and commitment could be fulfilled by a determined effort on the part of all concerned.

The hospitals that are involved in charity should know the difference between free service and good service. The patients would turn up only if the service is good. On the other hand good staff is not again free staff. Eventually, one should understand good service is timely delivery of quality service at reasonable cost. One should understand that the concept of quality of patient care is not fixed. It is the patients' gladness or contentment, which is dynamic. So, they should not misunderstand or underestimate the patient's satisfaction with free service. Thus, the objectives of charitable hospitals need to do a lot to meet people's aspirations.

\section{Conclusion}

It was uncovered in field of survey that the recurrence of visit to the doctor/specialist's facility was once in every 15 days if there should be an occurrence of $14 \%$ of the respondents while $66 \%$ of them answered to visit a doctor/hospital in any event once in a month. Subsequently, $80 \%$ of the respondents fell sick regularly. In slums, open channels, lack of sufficient sewerage, lack of civic amenities, dangerous 
drinking water and overall poor living conditions, consolidated with a high grouping of people are very common, which prompt more prominent occurrence of transmittable infections. These respondents living in slums held poor levels of hygiene, cleanliness and sanitation. Accordingly, they are inclined to transmittable infections. It was observed that many of them survived on daily wages and therefore, it was unrealistic for them to manage the cost of good quality food. This was likewise one of the reasons for high incidence of health issues because of poor immunity among these people. The cost factor was observed to be the most vital factor in instance of $99 \%$ respondents while choosing a doctor/ specialist's facility as most of them were daily wage earners. The second most vital paradigm evaluated by $70 \%$ of the respondents was the distance that they had to travel in order to access a doctor/ specialist's facility. As a result, preference for private clinics or charitable dispensaries in region was more grounded over public hospitals for minor illnesses as they could be accessed without acquiring any extra cost on commuting. If there should be an occurrence of $41 \%$ of the respondents, the time considers was the reason in choosing a dispensary or a hospital.

\section{References}

1. Blai B Jr (1964) An occupational study of job satisfaction and need satisfaction. J Exp Educ 32: 383-388.

2. Milton RB (1969) Work values and job satisfaction. J Appl Psychol 53: 456459.

3. Bose AB (1970) Problems of education development of Scheduled Tribes Man in India 1: 26-51.

4. Wong BA (1986) The Influence of Economic Liberalization on Health Care Access in the People's Republic of China.
5. Government of India (2002) National Human Development Report 2001. Bulletin on Rural Health Statistics in India, Oxford University Press, New Delhi, pp. 259.

6. Cassel J (1976) The contribution of the social environment to host resistance: the Fourth Wade Hampton Frost Lecture. Am J Epidemiol 104: 107-123.

7. Census of India (2001) Central Bureau of Health Intelligence. Directorate General of Health Services.

8. Ministry of Health and Family Welfare (2000) Health Information of India.

9. Chandrasekhar U, Chitra G (1990) Diet profiles and nutritive value of selected foods eaten by the Kota and Kadar tribes. Indian J Nutr Diet 27: 101-107.

10. Chang FR, Trivedi PK (2003) Economics of self-medication: theory and evidence. Health Econ 12: 721-739.

11. Chauhan A (1990) Tribal women and social change in India. A.C. Bros. pp. 84

12. Chelte AF, Hess P, Fanelli R, Ferri WP (1989) Corporate culture as an impediment to employee involvement-when you can't get there from here. Work Occup 16: 153-164.

13. Cronin and Taylor (1992) Measuring service quality re-examination

14. Dadibhavi RV, Bagalkoti ST (1994) Interstate Disparities in Health status in India.

15. Das NP, Bhavsar S, Patel R (2000) The growth and development of scheduled caste and scheduled tribe population in Gujarat and future prospects: Gujarat.

16. Das J, Hammer J (2007) Money for nothing: The dire straits of medical practice in Delhi, India. J Dev Econ 83.

17. (1999) Rediscovering satisfaction. J Mark 5-23. 